\title{
The immunoreactivity of TGF- $\beta 1$ in non-alcoholic fatty liver disease
}

\author{
Radoslaw Kempinski ${ }^{1}$, Katarzyna Neubauer ${ }^{1}$, Elzbieta Poniewierka ${ }^{1}$, \\ Maciej Kaczorowski ${ }^{2}$, Agnieszka Halon ${ }^{2}$
}
${ }^{1}$ Department of Gastroenterology and Hepatology, Wroclaw Medical University, Wroclaw, Poland
${ }^{2}$ Department of Pathomorphology and Oncological Cytology, Wroclaw Medical University, Wroclaw, Poland

\begin{abstract}
Introduction. Non-alcoholic fatty liver disease (NAFLD) is a common chronic liver disease which becomes a rapidly growing health problem in the Western countries. The development of the disease is most often connected to obesity. NAFLD is also considered as the hepatic manifestation of metabolic syndrome. Transforming growth factor $\beta 1$ (TGF- $\beta 1$ ) plays an important role in the pathogenesis of liver fibrosis, being involved in activation of hepatic stellate cells, stimulation of collagen gene transcription, and suppression of matrix metalloproteinase expression. The objective of the study was to evaluate by immunohistochemistry the expression of TGF- $\beta 1$ in the liver tissue of NAFLD patients and correlate it with anthropometric, biochemical and routine histological parameters.

Material and methods. The study group consisted of 48 patients with diagnosed NAFLD. Liver steatosis, NAFLD Activity Score (NAS) and METAVIR score of fibrosis were evaluated in liver biopsies. The immunoreactivity of TGF- $\beta 1$ was evaluated semi-quantitatively separately in portal, septal, lobular hepatocytic and lobular sinusoidal liver compartments. The results were analyzed in regard to patients' clinical and biochemical parameters. Results. Neither steatosis nor NAS correlated with TGF- $\beta 1$ expression in any liver compartment, whereas METAVIR score of fibrosis was associated with increased immunoreactivity of TGF- $\beta 1$ in most of the studied liver compartments. TGF- $\beta 1$ immunoreactivity showed positive correlation with patients' age and its expression in septal compartment disclosed positive correlation with body mass index, and waist and hip circumference. Hyaluronic acid serum level was positively and iron concentration was negatively associated with TGF- $\beta 1$ expression in the selected consecutive liver compartments.

Conclusions. The immunohistochemical expression of TGF- $\beta 1$ may be complementary to routine methods of liver fibrosis evaluation. (Folia Histochemica et Cytobiologica 2019, Vol. 57, No. 2, 74-83)
\end{abstract}

Key words: TGF- $\beta 1$; NAFLD; liver fibrosis; liver compartments; IHC; hyaluronic acid; serum iron

\section{Introduction}

Non-alcoholic fatty liver disease (NAFLD) is a common chronic liver disease which becomes a rapidly growing health problem in developed countries affecting approximately $30 \%$ of population [1].

\footnotetext{
Correspondence address: Radoslaw Kempinski, $\mathrm{MD}, \mathrm{PhD}$

Department of Gastroenterology and Hepatology

Wroclaw Medical University

Borowska 213, 50-556 Wroclaw, Poland

tel. +48 71733 2120; fax +48 717332129

e-mail: radoslaw.kempinski@umed.wroc.pl
}

Its worldwide prevalence continues to increase with the growing problem of obesity [2]. NAFLD involves several liver conditions: simple steatosis, non-alcoholic liver steatohepatitis (NASH), hepatic cirrhosis and hepatocellular carcinoma (HCC). NAFLD is strongly associated with the metabolic syndrome [3]. The course of NAFLD differs between patients and most of them do not develop more advanced forms of the disease. However, $20 \%$ of patients with NAFLD progress to NASH and $30 \%$ of patients with NASH have liver fibrosis [1]. Age above 50 years and preexisting fibrosis are well established factors that increase the risk of cirrhosis in the course of NAFLD [4]. 
Additionally, NAFLD-associated non-cirrhotic HCC is a currently recognized problem [5].

Transforming growth factor (TGF) $\beta 1$ is one of the most important cytokines accelerating liver fibrosis [6]. TGF- $\beta 1$ promotes activation of hepatic stellate cells (HSCs), stimulates collagen gene transcription, and suppresses expression of matrix metalloproteinases. Therefore, TGF- $\beta 1$ signaling represents a potential therapeutic target in liver fibrosis treatment. Additionally, TGF- $\beta 1$ signaling pathway can interfere with hepatocyte proliferation and accelerate HCC progression. TGF- $\beta 1$ has been reported to play both tumor-suppressive and tumor-promoting roles [7-9].

Although liver biopsy is still a gold standard to estimate fibrosis stage, new techniques are now under validation for noninvasive fibrosis evaluation, e.g. serum marker panels [10], elastography [11], and functional breath tests [12].

The objective of this study was to evaluate the expression of TGF- $\beta 1$ in the liver tissue of patients with NAFLD and to correlate it with anthropometric, biochemical and classical histological parameters.

\section{Material and methods}

Patients. The study group consisted of 48 consecutive patients with NAFLD diagnosed in Department of Gastroenterology and Hepatology, Wroclaw Medical University between 2015 and 2017. The diagnosis was made based on the American Association for the Study of Liver Diseases (AASLD) guidelines [13]. None of 48 consecutive patients with NAFLD had normal body weight index (BMI 18.5-25). Eighteen (40.9\%) patients were overweight (BMI 25-30) and $26(59.1 \%)$ were obese (BMI $>30)$. Mean age of the patients was 46.1 years; no significant difference in the mean age was found between sexes. Characteristics of the patients are shown in Table 1. NAFLD was confirmed by histological examination of liver biopsies ( $>5 \%$ of hepatocytes containing fat droplets). Indications for liver biopsy included suspicion of steatohepatitis or liver fibrosis in the course of steatosis. Other causes of steatosis were excluded: viral hepatitis, autoimmune hepatitis, hemochromatosis, Wilson's disease, $\alpha-1$ antitrypsin deficiency and drug-induced hepatic injury. Consumption of ethanol higher than $30 \mathrm{mg} /$ day for men and $20 \mathrm{mg} /$ day for women was also the exclusion criterion. Complete clinical examination with anthropometric measurements and laboratory sampling was performed in all subjects at the beginning of the study. The anthropometric data included body mass, height, body mass index (BMI) calculated as weight $(\mathrm{kg})$ divided by height squared $\left(\mathrm{m}^{2}\right)$, waist circumference (WC), hip circumference (HC), waist-to-hip ratio and waist-to-height ratio.
Laboratory tests. Standard blood morphology, liver biochemical tests, serum lipids, fasting glucose, insulin, C-reactive protein, glycated hemoglobin $\left(\mathrm{HbA}_{1 \mathrm{c}}\right)$, C-peptide, iron and ferritin concentrations were measured. Additionally, serum was collected for potential markers of inflammation/fibrosis in the liver: hyaluronic acid, fibronectin, alpha-2-macroglobulin, haptoglobin, apolipoprotein A1, TGF- $\beta 1$ and TNF. Homeostasis model assessment of insulin resistance (HOMA-IR) was calculated using the following formula: HOMA-IR $=$ fasting glucose $(\mathrm{mg} / \mathrm{dL}) \times$ fasting insulin $(\mu \mathrm{U} / \mathrm{mL}) / 405$ [14]. History of concomitant diseases/medication was obtained. The diagnosis of metabolic syndrome was established according to Adult Treatment Panel III criteria [15]. The study protocol was approved by local ethics committee with compliance to the Helsinki Declaration. Informed written consent was obtained from each patient before enrollment to the study.

Histopathology. Histological examinations of all samples were performed by the same pathologist. All specimens were considered representative (sample length $>1.5 \mathrm{~cm}$ ). After the percentage involvement by steatotic hepatocytes was assessed, the patients were divided into subgroups: 5-33\% mild, 33-66\% moderate or $>66 \%$ severe steatosis. NASH Clinical Research Network system for scoring activity and fibrosis in NAFLD was used to calculate NAFLD Activity Score (NAS) ranging 0-8 [16]. Patients with NAS score 0-2 were considered as not having NASH, patients with score 5-8 were diagnosed NASH. Activity scores 3 and 4 were noted as borderline cases (borderline NASH). The staging of fibrosis was assessed using METAVIR score [17] (F0: no fibrosis, F1: portal fibrosis without septa, F2: portal fibrosis with few septa, F3: numerous septa without cirrhosis, F4: cirrhosis).

Immunohistochemistry. From $10 \%$ formalin-fixed paraffin embedded blocks $5 \mu \mathrm{m}$-thick sections were cut with microtome and mounted on sialinized slides (code number S3003; DAKO, Glostrup, Denmark). Next, they underwent automated dewaxing, rehydration and heat-induced epitope retrieval in PT Link Pre-Treatment Module for Tissue Specimens (DAKO), with EnVision Target Retrieval Solution (DAKO) used for $30 \mathrm{~min}$ incubation at $97^{\circ} \mathrm{C}$. Immunohistochemical (IHC) reaction with TGF- $\beta 1$ rabbit polyclonal antibody (No. PA5-32628, 1:100 Thermo Scientific Pierce Products, Waltham, MA, USA) was performed in Autostainer Link 48 (DAKO) and EnVision FLEX/HRP system (DAKO) was used for detection. Positive and negative control slides were prepared. As a negative control, liver core biopsy was processed in the abovementioned sequences, but FLEX Mouse Negative Control, Ready-to-Use (DAKO) was used instead of the primary antibody. Human brain 
Table 1. Selected clinical characteristics of patients with non-alcoholic fatty liver disease $(\mathrm{n}=48)$

\begin{tabular}{|c|c|}
\hline Age (years) & $46.1 \pm 10.9(\mathrm{M}: 45.9 \pm 9.9 ; \mathrm{F}: 46.3 \pm 11.1)$ \\
\hline Sex (female/male) & $17 / 31(35.4 \% ; 54.6 \%)$ \\
\hline Weight $[\mathrm{kg}]$ & $93.0 \pm 16.7(\mathrm{M}: 95.6 \pm 14.4 ; \mathrm{F}: 90.1 \pm 12.4)$ \\
\hline BMI $\left[\mathrm{kg} / \mathrm{m}^{2}\right]$ & $30.9 \pm 4.0(\mathrm{M}: 30.1 \pm 3.6 ; \mathrm{F}: 32.9 \pm 4.2)$ \\
\hline $\mathrm{HC}[\mathrm{cm}]$ & $107.1 \pm 8.6(\mathrm{M}: 105 \pm 7.2 ; \mathrm{F}: 112.3 \pm 9.5)$ \\
\hline $\mathrm{WC}[\mathrm{cm}]$ & $107.6 \pm 9.3(\mathrm{M}: 107.0 \pm 9 ; \mathrm{F}: 109 \pm 9.7)$ \\
\hline WHR & $1.004 \pm 0.09(\mathrm{M}: 1.02 \pm 0.04 ; \mathrm{F}: 0.97 \pm 0.04)$ \\
\hline WHtR & $0.61 \pm 0.06(\mathrm{M}: 0.6 \pm 0.06 ; \mathrm{F}: 0.61 \pm 0.05)$ \\
\hline \multicolumn{2}{|l|}{ Serum values } \\
\hline Glucose $(<100 \mathrm{mg} / \mathrm{dL})$ & $112.9 \pm 47.1$ \\
\hline Insulin $(\mu \mathrm{U} / \mathrm{mL})$ & $13.1 \pm 10.2$ \\
\hline $\mathrm{HbA}_{1 \mathrm{c}}(3-6.5 \%)$ & $5.87 \pm 0.9$ \\
\hline C-peptide $[\mathrm{ng} / \mathrm{ml}]$ & $3.79 \pm 2.4$ \\
\hline $\operatorname{ALT}(<35 \mathrm{U} / \mathrm{I})$ & $73.3 \pm 33.6$ \\
\hline $\operatorname{AST}(<31 \mathrm{U} / \mathrm{I})$ & $53.0 \pm 26.5$ \\
\hline GGT $(<38 \mathrm{U} / \mathrm{I})$ & $82.8 \pm 47.6$ \\
\hline Alkaline phosphatase (30-120 U/I) & $96.4 \pm 37.1$ \\
\hline TG $(<150 \mathrm{mg} / \mathrm{dl})$ & $233.2 \pm 140.1$ \\
\hline Iron $(70-180 \mu \mathrm{g} / \mathrm{dl})$ & $103.42 \pm 38.1$ \\
\hline Hyaluronic acid [ng/ml] & $29.47 \pm 14.1$ \\
\hline Haptoglobin $[\mathrm{g} / \mathrm{l}]$ & $1.66 \pm 0.9$ \\
\hline TGF- $\beta 1$ [ng/ml] & $6.42 \pm 3.1$ \\
\hline HOMA-IR & $2.54 \pm 2.54$ \\
\hline \multicolumn{2}{|l|}{ Clinical status } \\
\hline Hypertension & $27(56.2 \%)$ \\
\hline Diabetes & $14(29.2 \%)$ \\
\hline Dyslipidemia & $20(41.7 \%)$ \\
\hline Metabolic syndrome & $19(39.6 \%)$ \\
\hline
\end{tabular}

Values represent mean $\pm \mathrm{SD}$ or the number of patients with percentages in parentheses. Abbreviations: BMI — body mass index; HC - hip circumference; WC — waist circumference ; WHR — waist to hip ratio; WHtR — waist to height ratio; ALT — alanine transaminase; AST — aspartate transaminase; GGT — gamma-glutamyl-transferase; TG — triglycerides; HOMA-IR — homeostasis model assessment of insulin resistance.

tissue was used for positive controls. Evaluation of TGF- $\beta 1$ expression was performed with Olympus BX41 microscope by the same pathologist. TGF- $\beta 1$ expression was evaluated in following compartments: portal (PC), septal (SC), lobular hepatocytic (LCH) and lobular sinusoidal (LCS). Compartments for the evaluation of IHC reactivity were distinguished by the authors based on the anatomical structure of the liver in attempt to diversify the significance of TGF- $\beta 1$ in various histological regions of this organ.

Evaluation of the intensity of TGF- $\beta 1$ immunoreactivity. The assessment of TGF- $\beta 1$ expression in each compartment was based on the intensity of the IHC reaction; specimens were given points according to the following scale: no re- activity -0 , weak reactivity -1 , moderate reactivity -2 , strong reactivity - 3. In LCH and LCS compartments, TGF- $\beta 1$ expression was also evaluated according to a modified scale of Remmele [18], in which two parameters were considered: percentage of cells with positive cytoplasmatic immunoreactivity (percentage of reactive area) and intensity of staining (Table 2). Final score (0-12 pts.), named Immunoreactive Score (IRS), was calculated by multiplication of points given for percentage of positive cells ( $0-4$ pts.) and intensity of reaction ( $0-3$ pts.).

Statistical analysis. Continuous, normally distributed variables were expressed as mean \pm standard deviation. Student's t-test was performed to compare the means between groups 
Table 2. Modified scale of Remmele used for evaluation of immunohistochemistry [18]

\begin{tabular}{|l|c|c|c|}
\hline Percentage of cells with positive cytoplasmatic reaction & Points & Intensity of color reaction & Points \\
\hline No cells with reaction & 0 & No reaction & 0 \\
\hline$<25 \%$ cells with positive reaction & 1 & Weak reaction & 1 \\
\hline $25-50 \%$ cells with positive reaction & 2 & Moderate reaction & 2 \\
\hline $51-75 \%$ cells with positive reaction & 3 & Intensive reaction & 3 \\
\hline$>75 \%$ with positive reaction & 4 & & \\
\hline
\end{tabular}
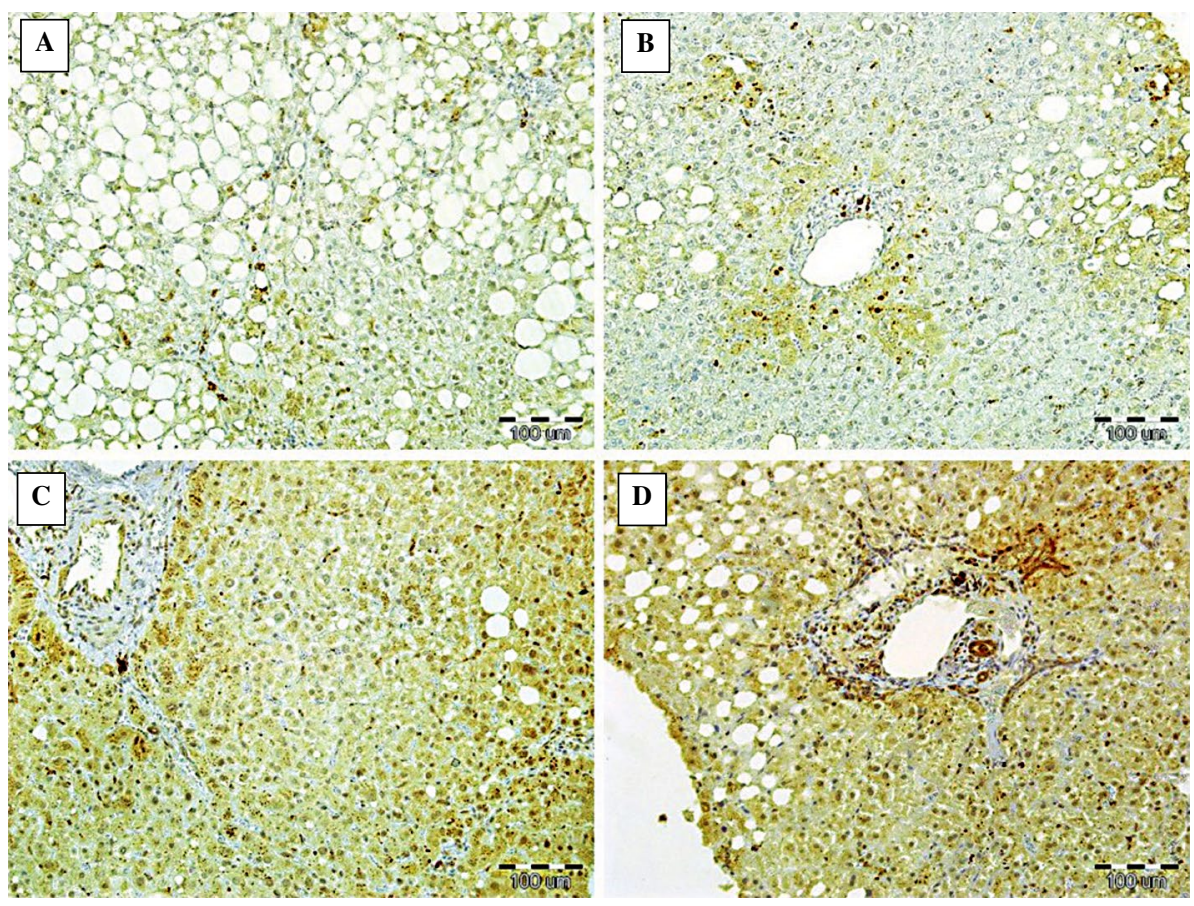

Figure 1. The immunoreactivity of TGF- $\beta 1$ in liver sections. A. Massive hepatic steatosis; low TGF- $\beta 1$ expression in lobular hepatocytic and lobular sinusoidal compartments. B. Centrilobular zone with mild steatosis; moderate TGF- $\beta 1$ immunoreactivity in lobular hepatocytic and lobular sinusoidal compartments, mostly adjacent to the central vein. C. Minimal hepatic steatosis, periportal and lobular zone; high TGF- $\beta 1$ expression in lobular hepatocytic compartment. D. Moderate hepatic steatosis, portal triad zone; high TGF- $\beta 1$ expression in portal and lobular hepatocytic compartments. TGF- $\beta 1$ immunoreactivity was visualized in the sections of human liver biopsies as described in Methods.

with normally distributed data. In non-parametric samples, Mann-Whitney U-test was used. Normality of distribution was evaluated with Shapiro-Wilk test. Associations between normally distributed data were analyzed using Pearson correlation coefficient and Spearman correlation was performed in non-parametric data series.

\section{Results}

\section{The immunoreactivity of TGF- $\beta 1$ in the classified liver compartments}

Cytoplasmic TGF- $\beta 1$ expression was observed in various cells of all analyzed liver compartments: besides expression in lobular hepatocytes, TGF- $\beta 1$ reactivity was present in parasinusoidal stellate cells, sinusoidal Kupffer cells, other infiltrating immune cells as well as fibroblasts in PC and SC (Fig. 1). The distribution of TGF- $\beta 1$ immunoreactivity in respective compartments, assessed as the intensity of the IHC reaction, is shown in Figure 2. The intensity of TGF- $\beta 1$ immunoreactivity was compared in pairs between consecutive compartments. The intensity of TGF- $\beta 1$ immunoreactivity was significantly lower in septal compartment compared with every other compartment (Mann-Whitney U-test, $p<0.001$, Fig. 3). Additionally, the TGF- $\beta 1$ immunoexpression in lobular hepatocytic compartment was significantly lower compared to either portal compartment or lobular 


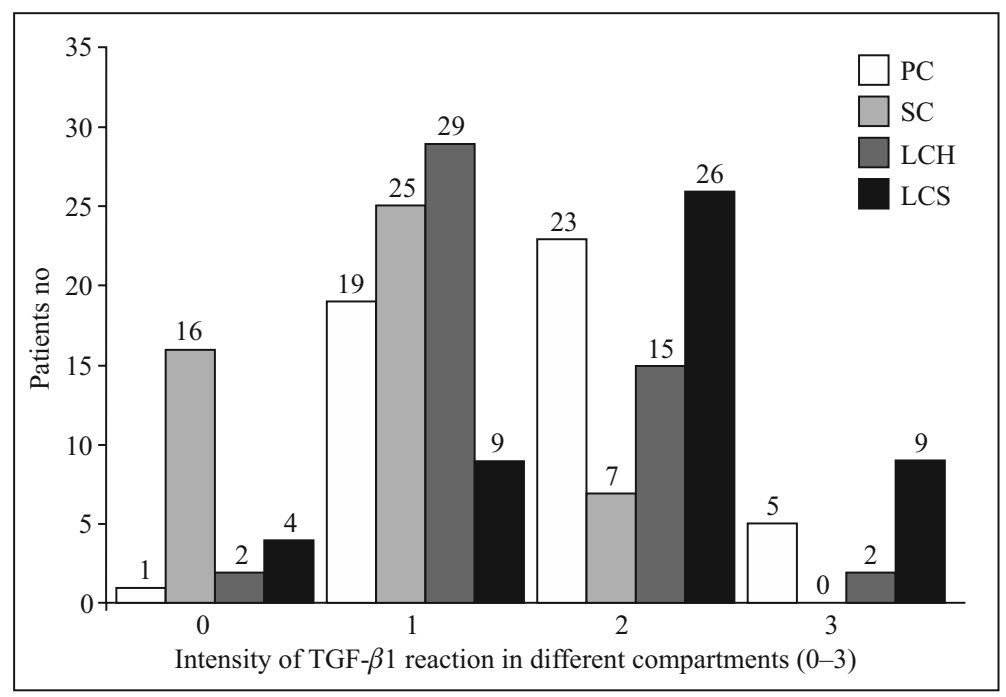

Figure 2. Distribution of the intensity of TGF- $\beta 1$ immunoreactivity in respective compartments of the human liver in patients with non-alcoholic fatty liver disease.

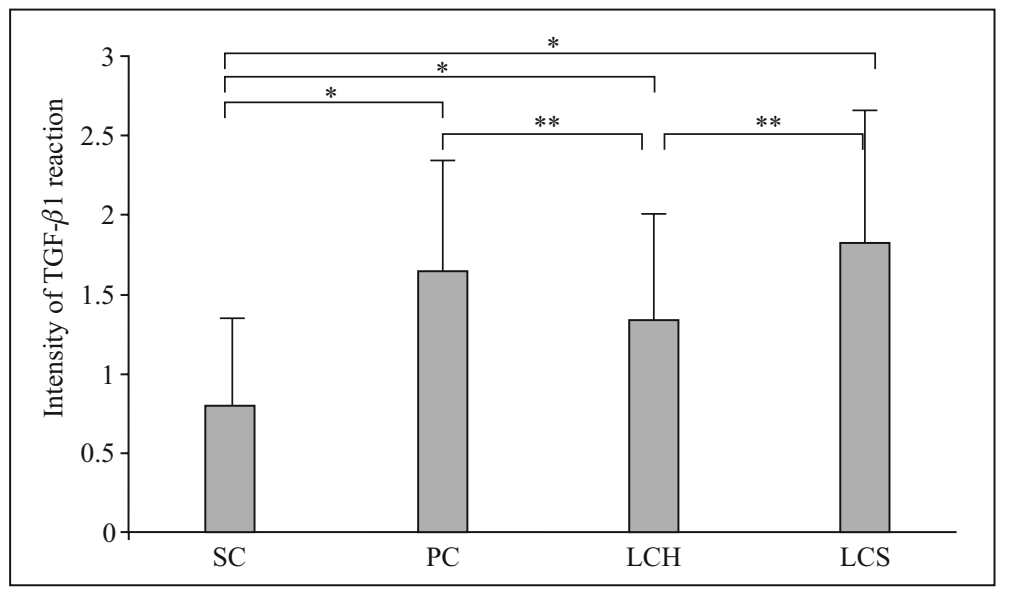

Figure 3. Mean intensity of TGF- $\beta$ expression in respective compartments of the human liver in patients with non-alcoholic fatty liver disease. Abbreviations: LCH — lobular hepatocytic; LCS - lobular sinusoidal; PC — portal; SC — septal). Data are presented as mean SD. ${ }^{*} \mathrm{p}<0.001$ Septal compartment (SC) compared to PC, LCH, LCS compartments. ${ }^{* *}$ p $<0.05$ LCH compared to PC and LCS compartments.

sinusoidal compartment (Mann-Whitney U-test, $p<0.05$, Fig. 3 ). The distribution of TGF- $\beta 1$ immunoreactivity in LCH and LCS, expressed by the IRS score, is shown in Figure 4.

In intercompartmental analysis of TGF- $\beta 1$ expression we observed positive correlations between intensity of staining in respective compartments (Table 3).

\section{TGF- $\beta 1$ immunoreactivity and clinical characteristics of the NAFLD patients}

Associations between TGF- $\beta 1$ expression and selected clinical parameters are shown in Table 4 . Interestingly, TGF- $\beta 1$ immunoexpression correlated with patients' age in most compartments. No significant differences between sexes were found concerning age. Natural differences in some anthropometric parameters were found between sexes (e.g. higher waist-to-hip ratio, i.e. WHR, in men). Moderate positive correlations were found between the intensity of reaction in septal compartment and BMI, waist and hip circumference $(\mathrm{p}<0.05)$.

TGF- $\beta 1$ immunoexpression and laboratory findings in NAFLD patients

The analysis of TGF- $\beta 1$ expression versus laboratory parameters revealed moderate negative correlation 


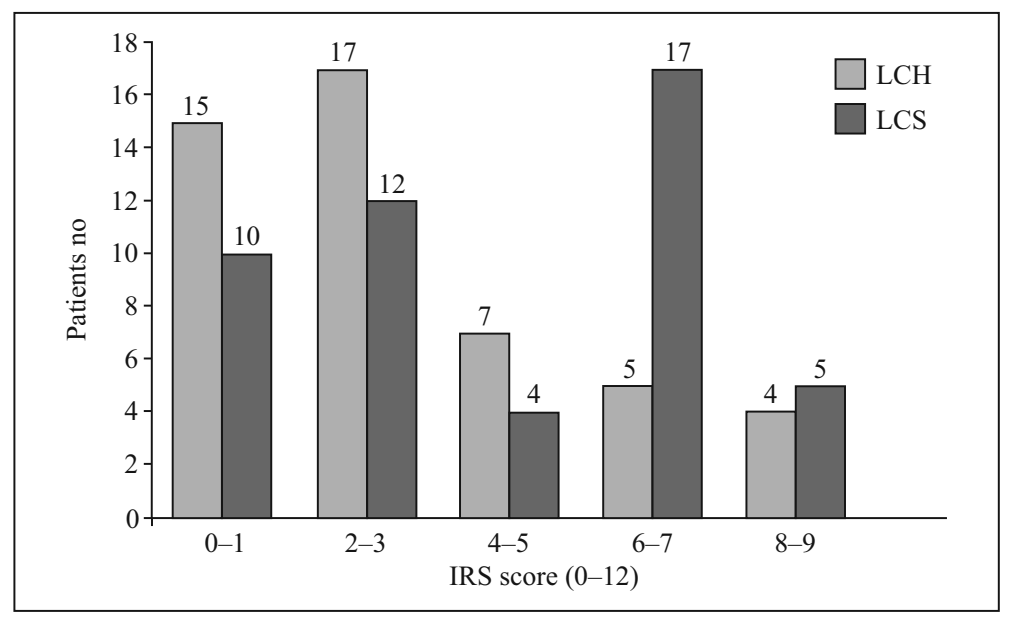

Figure 4. Immunoreactivity score (IRS) in lobular compartments of the human liver in patients with non-alcoholic fatty liver disease.

Table 3. Correlations between intensity of TGF- $\beta 1$ immunoreactivity in the analyzed liver compartments of liver biopsies in patients with non-alcoholic fatty liver disease

\begin{tabular}{|l|c|c|c|c|}
\hline & PC & SC & LCH & LCS \\
\hline PC & 1.0 & & & \\
\hline SC & $0.61^{*}$ & 1.0 & & \\
\hline LCH & $0.45^{*}$ & $0.62^{*}$ & 1.0 & \\
\hline LCS & $0.44^{*}$ & $0.46^{*}$ & $0.42^{*}$ & 1.0 \\
\hline
\end{tabular}

Values express Spearman correlation coefficients. Abbreviations: PC - portal compartment; SC - septal compartment; LCH - lobular hepatocytic compartment; LCS - lobular sinusoidal compartment. SIMILARLY AS IN TABLE $4 ;{ }^{*} \mathrm{p}<0.01$.

with serum iron levels. Negative correlations between iron levels and TGF- $\beta 1$ immunoreactivity were observed in SC, LCH and LCS, whereas moderate positive correlations with haptoglobin, hyaluronic acid and serum TGF- $\beta 1$ (Table 4 ). No correlations were found between TGF- $\beta 1$ expression in any compartment and following parameters: components of blood morphology, alanine transaminase, aspartate transaminase, gamma-glutamyl-transferase, alkaline phosphatase, serum lipids, ferritin concentration and HOMA (data not shown). Also, no correlations between the expression of TGF- $\beta 1$ in any compartment and fibronectin, alpha-2-macroglobulin, apolipoprotein A1 and TNF were found (data not shown).

\section{TGF- $\beta 1$ expression and histopathological characteristics}

Neither liver steatosis nor activity of NAFLD (NAS score) were associated with TGF- $\beta 1$ immunoreactivity. However, both the intensity and IRS of TGF- $\beta 1$ expression in $\mathrm{LCH}$ were weakly, positively associated with the stage of liver fibrosis. Similar weak association was observed in PC, whereas moderate correlation with fibrosis was found in SC (Table 4).

\section{Discussion}

Liver fibrosis results from the excessive accumulation of extracellular matrix proteins including collagen that occurs in most types of chronic liver diseases [19]. Fibrosis may affect also other organs such as kidneys and heart, leading to significant changes in their structure and function [20,21]. There is a wide range of factors causing fibrosis, such as infections, ischemia, radiation or injuries [22-24] and proinflammatory cytokines are thought to be involved in its initiation [25]. It was found that key roles in regulating promotion and acceleration of fibrosis are played by members of the TGF- $\beta$ superfamily [26]. The members of the TGF- $\beta$ family belong to the group of the most pleiotropic cytokines, involved in many physiological pathologic processes, e.g. inflammation, tissue repair, cell migration as well as cell differentiation and apoptosis [27]. Studies on TGF- $\beta$ functions led to development of targeted therapies in kidney and lung fibrosis $[28,29]$ and in cancer [30]. Accordingly, fibrosis in the course of NAFLD emerges as one of the possible therapeutic targets, next to hepatic steatosis and metabolic stress, bile acid-farnesoid $\mathrm{X}$ receptor axis, de novo lipogenesis, incretins- and fibroblast growth factors-dependent pathways, inflammation and injury [31].

Furthermore, it has been recently demonstrated that fibrosis stage affects liver-related mortality in patients with NAFLD [32]. Moreover, it predicted overall- and disease-specific survival among patients with NAFLD [33]. 
Table 4. Correlations between the intensity of TGF- $\beta 1$ immunoreactivity in respective liver compartments, age and selected anthropometric, laboratory and histopathological parameters

\begin{tabular}{|l|c|c|c|c|c|c|}
\hline & PC & SC & LCH & LCS & LCH-IRS & LCS-IRS \\
\hline Age & $0.29^{*}$ & $0.42^{* *}$ & 0.17 & 0.22 & $0.31^{*}$ & $0.34^{*}$ \\
\hline Anthropometric parameters & & & & & & \\
\hline Weight & 0.01 & 0.18 & 0.05 & 0.20 & 0.00 & 0.15 \\
\hline BMI & 0.20 & $0.49^{* *}$ & 0.10 & 0.24 & 0.14 & 0.25 \\
\hline HC & 0.22 & $0.53^{* *}$ & 0.25 & 0.16 & 0.23 & 0.21 \\
\hline WC & 0.18 & $0.43^{* *}$ & 0.07 & 0.23 & 0.13 & 0.24 \\
\hline WHR & -0.05 & -0.12 & -0.26 & 0.05 & -0.13 & 0.07 \\
\hline Serum parameters & & & & & & \\
\hline HbA 1 c & 0.19 & $0.31^{*}$ & 0.19 & -0.03 & 0.26 & 0.05 \\
\hline C-peptide & 0.20 & $0.31^{*}$ & 0.14 & 0.08 & 0.08 & 0.01 \\
\hline Iron & -0.11 & $-0.37^{* *}$ & $-0.38^{* *}$ & $-0.32^{* *}$ & $-0.32^{* *}$ & $-0.31^{* *}$ \\
\hline Hyaluronic acid & $0.36^{*}$ & $0.37^{* *}$ & 0.26 & 0.21 & $0.35^{*}$ & 0.16 \\
\hline Haptoglobin & 0.01 & $0.37^{* *}$ & 0.25 & 0.03 & 0.17 & 0.12 \\
\hline TGF- $\beta$ 1-serum & 0.21 & $0.38^{* *}$ & 0.26 & 0.15 & 0.13 & 0.22 \\
\hline Histopathological indices & & & & & & 0.13 \\
\hline Steatosis & 0.19 & 0.25 & 0.09 & 0.14 & 0.18 & 0.17 \\
\hline NAS score & -0.18 & -0.02 & -0.09 & -0.19 & -0.13 & -0.26 \\
\hline Fibrosis & $0.32^{*}$ & $0.41^{* *}$ & $0.28^{*}$ & 0.18 & $0.29^{*}$ & 0.16 \\
\hline
\end{tabular}

Values represent correlation coefficients. The intensity of the TGF- $\beta 1$ immunoreactivity was assessed as described in Methods. Abbreviations: same as in the legend to Table 1 and Table 3; LCH-IRS, lobular hepatocytic compartment assessed by ImmunoReactive Score; LCS-IRS lobular sinusoidal compartment assessed by ImmunoReactive Score. * $\mathrm{p}<0.05 ; * * \mathrm{p}<0.01$.

In recognition of the functional and structural heterogeneity of liver histology, we decided to evaluate TGF- $\beta 1$ expression in various compartments: periportal, septal and lobular. This division enabled characterization of the spatial distribution of TGF- $\beta 1$ in the liver tissue and more detailed analysis of possible correlations between TGF- $\beta 1$ reactivity and other clinicopathological parameters. In sinusoidal and hepatocytic compartments, TGF- $\beta 1$ staining was evaluated by two methods: intensity of immunoreactivity reaction and ImmunoReactive Score, as described in Methods). The latter technique additionally takes into account the percentage area of the reactive tissue. Overall, both methods led to similar results when TGF- $\beta 1$ expression was correlated with other clinicopathological parameters. The immunoexpression of TGF- $\beta 1$ was found in various cells of all hepatic compartments: hepatocytes, stellate cells, Kupffer cells, infiltrating immune cells and fibroblasts. Intercompartmental correlations were strongly positive. IHC reactivity of TGF- $\beta 1$ was the strongest in LCS, which highlights the role of Kupffer cells and parasinusoidal hepatic stellate cells as a source of fibrosis-driving TGF- $\beta 1$. The intensity of the IHC reaction was the least pronounced in SC, where the fibrosis evaluated in METAVIR scoring system is usually described. In this compartment TGF- $\beta 1$ expression showed strongest positive correlation with the stage of fibrosis (METAVIR). TGF- $\beta 1$ expression did not depend on the stage of liver steatosis. Also, the intensity of inflammation evaluated as NAS did not correlate with TGF- $\beta 1$ reactivity.

To the best of our knowledge, the distribution of TGF- $\beta 1$ has not been comprehensively studied in patients with NAFLD. However, Farrington et $a l$. studied TGF- $\beta 1$ expression in fibrotic livers in patients with biliary atresia [34]. They analyzed two areas, portal and lobular, and found that TGF- $\beta 1$ was present predominantly in the latter. Consistently, we observed highest TGF- $\beta 1$ reactivity in lobular compartments. However, periportal staining for TGF- $\beta 1$ was also prominent in our study. This discrepancy may be related to the depletion of bile ducts in advanced biliary atresia. Biliary epithelium is known to be a source of TGF- $\beta 1$ and thus contributes to fibrosis [35].

In standard histological liver scoring systems most attention is paid to the periportal and septal regions. Our study showed that TGF- $\beta 1$ distribution is diffused 
in liver lobules and not only limited to periportal and septal regions.

Considering anthropometrical data, we found that intensity of TGF- $\beta 1$ expression in SC correlated with BMI, waist and hip circumference, but not with absolute weight and waist-to-hip ratio. This indirectly suggests that BMI better than WHR predicts liver fibrosis. Our observation is in line with the reports of other authors. Angulo et al. implemented BMI in NAFLD Fibrosis Score, which is a well-established non-invasive system identifying liver fibrosis in NAFLD patients [36].

In our study we correlated selected biochemical parameters with the intensity of TGF- $\beta 1$ expression in the liver. We found positive associations with serum concentrations of $\mathrm{HbA}_{1 \mathrm{c}}$, C-peptide and hyaluronic acid, haptoglobin, and TGF- $\beta 1$ in septal compartment. This is not surprising since haptoglobin in wellknown marker of liver fibrosis and is incorporated in Fibrotest formula [37]. Serum concentration of hyaluronic acid seems to be biomarker of fibrosis in chronic liver diseases of different etiologies [38] such as non-alcoholic fatty liver disease [39], alcoholic fatty liver disease [40], and viral hepatitis [41].

An interesting, unexpected observation was the finding of a reverse correlation between TGF- $\beta 1 \mathrm{im}$ munoreactivity in most liver compartments and serum iron concentration. Trying to explain this phenomenon in humans we conjecture on a possible negative feedback mechanism that limits liver fibrosis. TGF- $\beta 1$ was recently recognized as an activator of hepcidin mRNA expression in isolated human hepatocytes [42]. Hepcidin maintains serum iron concentration by controlling dietary uptake of iron from duodenal enterocytes. It binds to cellular ferroportin to trigger its internalization and degradation, which blocks the transport of iron from enterocytes to portal circulation [43]. TGF- $\beta 1$ downregulates iron serum level in a hepcidin-dependent mechanism [44] which might explain the inverse correlation between iron levels and TGF- $\beta 1$ expression in our study. However, in an animal model Han et al. [45] showed decreased activation of hepatic stellate cells and TGF- $\beta 1$ effect by hepcidin. The authors demonstrated an inhibition of Smad3 phosphorylation in HSCs by hepcidin which may account for the anti-fibrotic effect of hepcidin. Based on this experimental study, a new model of fibrosis downregulation can be proposed: activation of HSCs results in TGF- $\beta 1$ synthesis and secretion that increases hepcidin expression. The overexpression of hepcidin, in turn, downregulates HSCs activation and thus self-limits liver fibrosis. Thus, studies of new fibrosis markers may lead not only to the improvement of the scoring systems but also to the development of the new therapeutic strategies. It has to be noted that one of the limitations of our study is fact that majority of patients were men although this is consistent with the results of the epidemiological studies [46].

\section{Conclusions}

TGF- $\beta 1$ might be a promising immunohistochemical marker of the liver fibrosis in NAFLD patients; however, further studies on larger group of patients with NAFLD are required.

The assessment of the immunohistochemical reactivity of TGF- $\beta 1$ can be complementary to routine methods of liver fibrosis evaluation.

\section{Acknowledgments}

The study was supported by Polish National Science Center grant No NN 519463239.

\section{Disclosure of conflict of interest}

The authors declare no competing interests.

\section{References}

1. Vernon G, Baranova A, Younossi ZM. Systematic review: the epidemiology and natural history of non-alcoholic fatty liver disease and non-alcoholic steatohepatitis in adults. Aliment Pharmacol Ther. 2011; 34(3): 274-285, doi: 10.1111/j.13652036.2011.04724.x, indexed in Pubmed: 21623852.

2. Corey KE, Kaplan LM. Obesity and liver disease: the epidemic of the twenty-first century. Clin Liver Dis. 2014; 18(1): 1-18, doi: 10.1016/j.cld.2013.09.019, indexed in Pubmed: 24274861.

3. Musso G, Gambino R, Bo S, et al. Should nonalcoholic fatty liver disease be included in the definition of metabolic syndrome? A cross-sectional comparison with Adult Treatment Panel III criteria in nonobese nondiabetic subjects. Diabetes Care. 2008; 31(3): 562-568, doi: 10.2337/dc07-1526, indexed in Pubmed: 18056890.

4. Argo CK, Northup PG, Al-Osaimi AMS, et al. Systematic review of risk factors for fibrosis progression in non-alcoholic steatohepatitis. J Hepatol. 2009; 51(2): 371-379, doi: 10.1016/j. jhep.2009.03.019, indexed in Pubmed: 19501928.

5. Perumpail RB, Liu A, Wong RJ, et al. Pathogenesis of hepatocarcinogenesis in non-cirrhotic nonalcoholic fatty liver disease: Potential mechanistic pathways. World J Hepatol. 2015; 7(22): 2384-2388, doi: 10.4254/wjh.v7.i22.2384, indexed in Pubmed: 26464753.

6. Inagaki Y, Okazaki I. Emerging insights into Transforming growth factor beta Smad signal in hepatic fibrogenesis. Gut. 2007; 56(2): 284-292, doi: 10.1136/gut.2005.088690, indexed in Pubmed: 17303605.

7. Seoane J, Gomis RR. TGF- Family Signaling in Tumor Suppression and Cancer Progression. Cold Spring Harb Perspect Biol. 2017; 9(12), doi: 10.1101/cshperspect.a022277, indexed in Pubmed: 28246180.

8. Bellam N, Pasche B. Tgf-beta signaling alterations and colon cancer. Cancer Treat Res. 2010; 155: 85-103, doi: 10.1007/9781-4419-6033-7_5, indexed in Pubmed: 20517689.

9. Shi C, Chen Y, Chen $\mathrm{Y}$, et al. $\mathrm{CD} 4^{+} \mathrm{CD} 25^{+}$regulatory T cells promote hepatocellular carcinoma invasion via TGF- $\beta 1$-in- 
duced epithelial-mesenchymal transition. OncoTargets and Therapy. 2018; Volume 12: 279-289, doi: 10.2147/ott.s172417.

10. Zhou JH, Cai JJ, She ZG, et al. Noninvasive evaluation of nonalcoholic fatty liver disease: Current evidence and practice. World J Gastroenterol. 2019; 25(11): $1307-$ -1326, doi: 10.3748/wjg.v25.i11.1307, indexed in Pubmed: 30918425.

11. Mikolasevic I, Orlic L, Franjic N, et al. Transient elastography (FibroScan $(\circledR))$ with controlled attenuation parameter in the assessment of liver steatosis and fibrosis in patients with nonalcoholic fatty liver disease - Where do we stand? World J Gastroenterol. 2016; 22(32): 7236-7251, doi: 10.3748/wjg. v22.i32.7236, indexed in Pubmed: 27621571.

12. Kempiński R, Neubauer K, Wieczorek S, et al. 13C-Methacetin Breath Testing in Patients with Non-Alcoholic Fatty Liver Disease. Adv Clin Exp Med. 2016; 25(1): 77-81, doi: 10.17219/ acem/60878, indexed in Pubmed: 26935501.

13. Chalasani N, Younossi Z, Lavine JE, et al. The diagnosis and management of non-alcoholic fatty liver disease: practice Guideline by the American Association for the Study of Liver Diseases, American College of Gastroenterology, and the American Gastroenterological Association. Hepatology. 2012; 55: 2005-2013, doi: 10.1053/j.gastro.2012.04.001; indexed in Pubmed: 22488764

14. Okita K, Iwahashi H, Kozawa J, et al. Homeostasis model assessment of insulin resistance for evaluating insulin sensitivity in patients with type 2 diabetes on insulin therapy. Endocrine Journal. 2013; 60(3): 283-290, doi: 10.1507/endocrj.ej12-0320.

15. Executive Summary of the Third Report of the National Cholesterol Education Program (NCEP) Expert Panel on Detection, Evaluation, and Treatment of High Blood Cholesterol in Adults (Adult Treatment Panel III) JAMA. 2001; 285(19): 2486-2497, doi: 10.1001/jama.285.19.2486.

16. Kleiner D, Brunt E, Natta MV, et al. Design and validation of a histological scoring system for nonalcoholic fatty liver disease. Hepatology. 2005; 41(6): 1313-1321, doi: 10.1002/ hep.20701.

17. Bedossa $\mathrm{P}$, Poynard T. An algorithm for the grading of activity in chronic hepatitis C. The METAVIR Cooperative Study Group. Hepatology. 1996; 24(2): 289-293, doi: 10.1002/ hep.510240201, indexed in Pubmed: 8690394.

18. Remmele W, Schicketanz KH. Immunohistochemical determination of estrogen and progesterone receptor content in human breast cancer. Computer-assisted image analysis (QIC score) vs. subjective grading (IRS). Pathol Res Pract. 1993; 189(8): 862-866, doi: 10.1016/S0344-0338(11)81095-2, indexed in Pubmed: 8302707.

19. Bataller R, Brenner DA. Liver fibrosis. J Clin Invest. 2005; 115(2): 209-218, doi: 10.1172/JCI24282, indexed in Pubmed: 15690074.

20. Tanaka T. A mechanistic link between renal ischemia and fibrosis. Med Mol Morphol. 2017; 50(1): 1-8, doi: 10.1007/ s00795-016-0146-3, indexed in Pubmed: 27438710.

21. Frohlich ED. Fibrosis and ischemia: the real risks in hypertensive heart disease. Am J Hypertens. 2001; 14(6 Pt 2): 194S-199S, doi: 10.1016/s0895-7061(01)02088-x, indexed in Pubmed: 11411756

22. Martin P, Nunan R. Cellular and molecular mechanisms of repair in acute and chronic wound healing. Br J Dermatol. 2015; 173(2): 370-378, doi: 10.1111/bjd.13954, indexed in Pubmed: 26175283.

23. Stubblefield MD. Clinical Evaluation and Management of Radiation Fibrosis Syndrome. Phys Med Rehabil Clin N Am.
2017; 28(1): 89-100, doi: 10.1016/j.pmr.2016.08.003, indexed in Pubmed: 27913002.

24. Bacmeister L, Schwarzl M, Warnke S, et al. Inflammation and fibrosis in murine models of heart failure. Basic Res Cardiol. 2019; 114(3): 19, doi: 10.1007/s00395-019-0722-5, indexed in Pubmed: 30887214.

25. Pérez L, Muñoz-Durango N, Riedel CA, et al. Endothelial-to-mesenchymal transition: Cytokine-mediated pathways that determine endothelial fibrosis under inflammatory conditions. Cytokine Growth Factor Rev. 2017; 33: 41-54, doi: 10.1016/j.cytogfr.2016.09.002, indexed in Pubmed: 27692608.

26. Walton KL, Johnson KE, Harrison CA. Targeting TGF- $\beta$ Mediated SMAD Signaling for the Prevention of Fibrosis. Front Pharmacol. 2017; 8: 461, doi: 10.3389/fphar.2017.00461, indexed in Pubmed: 28769795.

27. Biernacka A, Dobaczewski M, Frangogiannis NG. TGF- $\beta$ signaling in fibrosis. Growth Factors. 2011; 29(5): 196-202, doi: 10.3109/08977194.2011.595714, indexed in Pubmed: 21740331.

28. Isaka Y. Targeting TGF- $\beta$ Signaling in Kidney Fibrosis. Int J Mol Sci. 2018; 19(9), doi: 10.3390/ijms19092532, indexed in Pubmed: 30150520.

29. Fernandez IE, Eickelberg O. The impact of TGF- $\beta$ on lung fibrosis: from targeting to biomarkers. Proc Am Thorac Soc. 2012; 9(3): 111-116, doi: 10.1513/pats.201203-023AW, indexed in Pubmed: 22802283.

30. Xie F, Ling Li, van Dam H, et al. TGF- $\beta$ signaling in cancer metastasis. Acta Biochim Biophys Sin (Shanghai). 2018; 50(1): 121-132, doi: 10.1093/abbs/gmx123, indexed in Pubmed: 29190313.

31. Rotman Y, Sanyal AJ. Current and upcoming pharmacotherapy for non-alcoholic fatty liver disease. Gut. 2017; 66(1): 180-190, doi: 10.1136/gutjnl-2016-312431, indexed in Pubmed: 27646933.

32. Dulai PS, Singh S, Patel J, et al. Increased risk of mortality by fibrosis stage in nonalcoholic fatty liver disease: Systematic review and meta-analysis. Hepatology. 2017; 65(5): 1557-1565, doi: 10.1002/hep.29085, indexed in Pubmed: 28130788.

33. Ekstedt M, Hagström H, Nasr P, et al. Fibrosis stage is the strongest predictor for disease-specific mortality in NAFLD after up to 33 years of follow-up. Hepatology. 2015; 61(5): 1547-1554, doi: 10.1002/hep.27368, indexed in Pubmed: 25125077.

34. Farrington C, Novak D, Liu C, et al. Immunohistochemical localization of transforming growth factor $\beta$ - 1 and its relationship with collagen expression in advanced liver fibrosis due to biliary atresia. Clin Exp Gastroenterol. 2010; 3: 185-191, doi: 10.2147/CEG.S14220, indexed in Pubmed: 21694865.

35. Sedlaczek N, Jia JD, Bauer M, et al. Proliferating bile duct epithelial cells are a major source of connective tissue growth factor in rat biliary fibrosis. Am J Pathol. 2001; 158(4): 1239-1244, doi: 10.1016/S0002-9440(10)64074-6, indexed in Pubmed: 11290541.

36. Angulo P, Hui JM, Marchesini G, et al. The NAFLD fibrosis score: a noninvasive system that identifies liver fibrosis in patients with NAFLD. Hepatology. 2007; 45(4): 846-854, doi: 10.1002/hep.21496, indexed in Pubmed: 17393509.

37. Vilar-Gomez E, Chalasani N. Non-invasive assessment of non-alcoholic fatty liver disease: Clinical prediction rules and blood-based biomarkers. J Hepatol. 2018; 68(2): 305-315, doi: 10.1016/j.jhep.2017.11.013, indexed in Pubmed: 29154965.

38. Orasan OH, Ciulei G, Cozma A, et al. Hyaluronic acid as a biomarker of fibrosis in chronic liver diseases of different etiologies. Clujul Med. 2016; 89(1): 24-31, doi: 10.15386/ cjmed-554, indexed in Pubmed: 27004022. 
39. Santos VN, Leite-Mór MMB, Kondo M, et al. Serum laminin, type IV collagen and hyaluronan as fibrosis markers in non-alcoholic fatty liver disease. Braz J Med Biol Res. 2005; 38(5): 747-753, doi: 10.1590/s0100-879x2005000500012, indexed in Pubmed: 15917956.

40. Sowa JP, Atmaca Ö, Kahraman A, et al. Non-invasive separation of alcoholic and non-alcoholic liver disease with predictive modeling. PLoS One. 2014; 9(7): e101444, doi: 10.1371/ journal.pone.0101444, indexed in Pubmed: 24988316.

41. Halfon P, Bourlière M, Pénaranda G, et al. Accuracy of hyaluronic acid level for predicting liver fibrosis stages in patients with hepatitis C virus. Comp Hepatol. 2005; 4: 6, doi: 10.1186/1476-5926-4-6, indexed in Pubmed: 16008833 .

42. Chen S, Feng T, Vujić Spasić M, et al. Transforming Growth Factor $\beta 1$ (TGF- $\beta 1$ ) Activates Hepcidin mRNA Expression in Hepatocytes. J Biol Chem. 2016; 291(25): 13160-13174, doi: 10.1074/jbc.M115.691543, indexed in Pubmed: 27129231.

43. Ganz T, Nemeth E. Hepcidin and iron homeostasis. Biochim Biophys Acta. 2012; 1823(9): 1434-1443, doi: 10.1016/j.bbamcr.2012.01.014, indexed in Pubmed: 22306005.

44. Sangkhae V, Nemeth E. Regulation of the Iron Homeostatic Hormone Hepcidin. Adv Nutr. 2017; 8(1): 126-136, doi: 10.3945/an.116.013961, indexed in Pubmed: 28096133.

45. Han CY, Koo JaH, Kim SH, et al. Hepcidin inhibits Smad3 phosphorylation in hepatic stellate cells by impeding ferroportin-mediated regulation of Akt. Nat Commun. 2016; 7: 13817, doi: 10.1038/ncomms13817, indexed in Pubmed: 28004654.

46. Browning JD, Szczepaniak LS, Dobbins R, et al. Prevalence of hepatic steatosis in an urban population in the United States: impact of ethnicity. Hepatology. 2004; 40(6): 1387-1395, doi: 10.1002/hep.20466, indexed in Pubmed: 15565570.

Submitted: 11 April, 2019

Accepted after reviews: 24 May, 2019 Available as AoP: 12 June, 2019 